\title{
Article
}

\section{The Correlation amongst Salty Taste Preference and Overactive Bladder Symptoms in Female Individuals}

\author{
Jin-Won Noh ${ }^{1}$, Kyoung-Beom Kim ${ }^{1}{ }^{1}$, Jae Heon Kim ${ }^{2, *}$ a and Young Dae Kwon ${ }^{3} \mathbb{C}$ \\ 1 Department of Health Administration, Dankook University, Cheonan 31116, Korea; \\ jinwon.noh@gmail.com (J.-W.N.); aefile01287@korea.ac.kr (K.-B.K.) \\ 2 Department of Urology, Soonchunhyang University Seoul Hospital, Soonchuhyang University Medical \\ College, 59, Daesagwan-ro, Yongsan-gu, Seoul 140-743, Korea \\ 3 Department of Humanities and Social Medicine, College of Medicine and Catholic Institute for Healthcare \\ Management, The Catholic University of Korea, Seoul 06591, Korea; healthcare@catholic.ac.kr \\ * Correspondence: piacekjh@hanmail.net; Tel.: +82-2-709-3890; Fax: +82-2-710-3293-59
}

Citation: Noh, J-W.; Kim, K.-B.; Kim, J.H.; Kwon, Y.D. The Correlation amongst Salty Taste Preference and Overactive Bladder Symptoms in Female Individuals. Int. J. Environ. Res. Public Health 2021, 18, 518 https://doi.org/10.3390/ijerph18 020518

Received: 22 December 2020

Accepted: 8 January 2021

Published: 10 January 2021

Publisher's Note: MDPI stays neutral with regard to jurisdictional clai$\mathrm{ms}$ in published maps and institutional affiliations.

Copyright: $\odot 2021$ by the authors. Licensee MDPI, Basel, Switzerland. This article is an open access article distributed under the terms and conditions of the Creative Commons Attribution (CC BY) license (https:// creativecommons.org/licenses/by/ $4.0 /)$.

\begin{abstract}
Sodium intake could have an indirect effect on storage symptoms as it is an established fact that it has a correlation to hypertension (HTN). However, clinical support for the correlation of sodium intake to STORAGE symptom remains scarce. Therefore, the present work sought to determine how sodium intake and $\mathrm{OAB}$ symptom seriousness were correlated in female individuals based on a cross-sectional research design. Data from 115,578 respondents chosen from 228,921 individuals enrolled in the Korean Community Health Survey (KCHS) were subjected to cross-sectional analysis. The correlation amongst sodium intake and STORAGE symptom was assessed on the basis of estimates of the incidence rate ratio (IRR) with 95\% confidence interval (CI). Furthermore, joint correspondence analysis (JCA) was conducted to investigate how a predilection for salty taste was associated with several factors, including STORAGE symptom, socio-economic factors, comorbidities, and dietary habits. By comparison to respondents indicating a neutral predilection for salty taste, those who indicated a predilection for bland and salty taste were $7.1 \%$ (IRR $=1.071, p<0.001,95 \%$ $\mathrm{CI}=1.045-1.097)$ and $20.5 \%(\mathrm{IRR}=1.205, p<0.001,95 \% \mathrm{CI}=1.177-1.234)$ more probable to experience severe STORAGE symptom, within an adjusted model with multiple variables. JCA confirmed the existence of a correlation between predilection for salty taste and STORAGE symptom. A close correlation was established to exist between predilection for salty taste and lower urinary tract symptoms (LUTS), such as voiding and storage symptoms and nocturia. Moreover, sodium intake was found to be a risk factor for LUTS seriousness in both excessive and deficient amount.
\end{abstract}

Keywords: sodium; dietary; overactive bladder; lower urinary tract symptoms

\section{Introduction}

Both nutrients of fruit and vegetable origin and micronutrients serve as antioxidants and influence lower urinary tract symptoms (LUTS) [1,2]. The topic has been investigated in a few studies, but the findings have been inconsistent, particularly in relation to LUTS. The latest studies in the field of medicine have extensively explored sodium intake in relation to various conditions, such as hypertension (HTN), cardiovascular disease (CVD), and chronic kidney disease (CKD) [3,4]. Due to its direct association with CVD-related death, sodium intake is a significant health matter worldwide $[5,6]$.

There are two aspects that can clarify the potential correlation amongst sodium intake and LUTS, namely, the indirect impact of sodium intake through its influence on HTN [4,7] and the direct impact on the epithelial sodium channel of the bladder [8,9]. Sodium intake is such an important risk factor for HTN occurrence or worsening that it has led to the classification of individuals with HTN into two groups with and without sensitivity to sodium intake. 
In cases of LUTS, those with HTN showed a greater preponderance of urinary storage symptom compared to those who did not suffer from HTN [3]. Sodium intake acts indirectly in the context of LUTS, causing the autonomic nerve system to become hyperactive, particularly with regard to prostate and bladder innervation [10]. Furthermore, alpha blockers may become less effective therapeutically due to HTN triggered by sodium intake [8]. It was found that, of the various nutrients, protein intake and sodium intake respectively constituted a risk factor for worsening voiding symptom and storage symptom [2,11]. Meanwhile, empirical work is the basis for revealing the direct impact of sodium intake within a LUTS context [4]. Storage symptoms can be stimulated by elevated sodium intake through epithelial sodium channel upregulation.

A possible correlation between sodium intake and LUTS, particularly overactive bladder $(\mathrm{OAB})$ and other storage symptoms, has been signalled by earlier our research [12]. Moreover, evidence has been produced regarding a close association between a predilection for salty taste and LUTS, such as voiding and storage symptoms and nocturia, with sodium being a risk factor for LUTS seriousness in both excessive and deficient amount [12]. However, this correlation has so far not been investigated in the case of female subjects.

The present paper explores the hypothesis that sodium predilection may have an indirect effect on storage symptom by causing disruptions to the circulation system, such as excessive activation of the adrenergic nerve system and direct bladder epithelium stimulation. To this end, analysis focuses on how sodium predilection and storage symptom are correlated after consideration of various socioeconomic factors.

\section{Methods}

\subsection{Data and Subjects}

This study utilized data obtained from the 2012 Korean Community Health Survey (KCHS). The KCHS was conducted annually since 2008 organized by the Korean Centers for Disease Control and Prevention. The objectives of KCHS to produce community-based comparable health statistics for evaluation of diseases prevention program and community health promotion. To extract representative samples, the KCHS used a multistage sampling design [13]. This study was carried out using data from 115,578 participants, after excluding 113,343 respondents those who male $(n=102,898)$, and who have missing data in Overactive Bladder Symptom Score (OABSS), salty taste preferences, or covariates $(n=10,445)$ from the 228,921 participants in the 2012 KCHS (Figure 1).

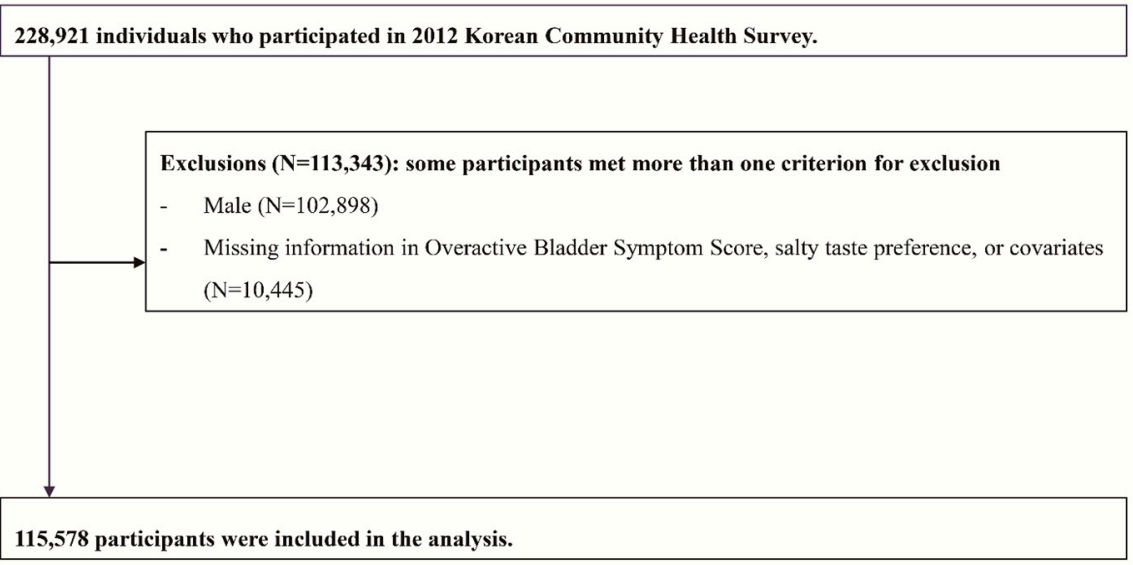

Figure 1. Inclusion and exclusion in the study population.

\subsection{Measurements}

The outcome variable, storage symptoms based on responses from the Korean version of OABSS Questionnaire on KCHS [14]. The OABSS is comprised of four questions that assess symptoms of storage, daytime frequency (How many times do you typically urinate from waking in the morning until sleeping at night?), night time frequency (How many 
times do you typically wake up to urinate from sleeping at night until waking in the morning?), urgency (How often do you have a sudden desire to urinate, which is difficult to defer?), and urge incontinence (How often do you leak urine because you cannot defer the sudden desire to urinate?) The total score ranges from 0 to 15 , higher score indicates severe storage symptoms. The total score was categorized into mild $(\leq 5)$, moderate $(6$ to $11)$, or severe $(12 \leq)$ storage symptoms [15]. The exposure variable, salty taste preference was measured by self-rated 5-point Likert scale. It was categorized into (very) salty, neutral, and (very) blandly.

Covariates considered socio-demographic factors, comorbidities, and dietary behaviors. Socio-demographics included age, marital status, education level, household income, and residential area. Age was consisting of seven groups from "19 to 29 years old" in subsequent 10-year intervals up to "90 years old or older." Marital status was classified into three categories as corresponding to "married", "separated, divorced, or widowed", or "never married." Education level were based on highest level completed and grouped as "elementary school graduate or lower", "middle school graduate", "high school graduate", and "college graduate or higher." Household income was divided into quartile. Residential area was classified into "capital", "urban", and "rural", based on 16 governmental administrative districts. In consideration of comorbidities, hypertension, diabetes, and dyslipidemia which known as highest degree of prevalence rate among adults were included [16]. Information of comorbidities was ascertained through self-report of a physician's diagnosis. Dietary behaviors included breakfast eating. it was ascertained using the question, "How many days do you eat the breakfast in last week?" Response was categorized as "5-7 days", "1-4 days", or "Never eat in last week."

\subsection{Statistical Analysis}

To summarize the socio-demographic, comorbidities, and dietary behavior characteristics of study participants according to salty taste preference, descriptive analysis was performed. The frequency and weighted proportion were reported as descriptive statistics. A Chi-squared test was performed to identify the proportion differences by salty taste preference among OABSS and covariates.

To explore the relationship between salty taste preference, storage symptom, socioeconomic, comorbidity, and dietary behavior in multifactorial manner, a joint correspondence analysis (JCA) was carried out. The JCA visualizes degree of clustering of points in coordinate plot at the level of the response categories of each variable [17]. As guidelines for interpreting the relationships between variables, degree of clustering of points on the JCA plot in terms of their angle from the centroid and points in the same quadrant can be used [18]. To investigate the relationship between OABSS and salty taste preference among Korean female adults, two sets of negative binomial regression models were fitted. The model I adjusted for age, and model II additionally adjusted for marital status, education level, household income, residential area, hypertension, diabetes mellitus, dyslipidemia, and breakfast eating. The adjusted incidence rate ratio (IRR) with $95 \%$ confidence intervals (CI) were reported. A sample design and benchmark weight were employed in analyses to account for complex sampling design of KCHS and ensure the produced estimates are nationally representative of the South Korean female population. The data were analyzed using Stata/MP 16.1 (StataCorp LP, College Station, TX, USA) and $\alpha=0.05$ (two-tailed) were considered to determine the statistical significance.

\subsection{Ethics Statement}

Procedures of this study were reviewed and approved by the Institutional Review Board of Soonchunhyang University Seoul Hospital with a waiver for informed consent (2018-12-011). The study protocol of KCHS was reviewed and approved by the institutional review board of Korean Centers for Disease Control and Prevention (2010-02CON-22-P). The privacy risk to the participants is minimized because KCHS data was anonymized. The KCHS data is openly accessible at national public repository (http://chs.cdc.go.kr). 


\section{Results}

Table 1 summarizes the general characteristics of study participants by salty taste preference. Among 115,578 South Korean female study participants, 60,533 (51.8\%) were reported "neutral", 27,292 (24.4\%) were "blandly", and 27,753 (23.8\%) were "salty" as their salty taste preference. About 6809 (5.9\%) of participants had moderate/severe STORAGE symptoms. A relatively small proportion of participants reported their salty taste preference as "blandly" in those who younger (age 19-29) or older (90 or higher) compared with middle-aged, unmarried, low-educated, in poverty, live in urbanized area, having comorbidities, skipping breakfast, having more frequent storage symptoms, and severe storage severity. The distribution of salty taste preference was significantly differed by age, marital Status, education Level, household income, residential area, hypertension, diabetes, dyslipidemia, frequency of weekly breakfast eating, storage symptoms (daytime frequency, nighttime frequency, urgency, and urge incontinence), and storage severity $(p<0.05)$.

Table 1. Characteristics of study participants by salty taste preference.

\begin{tabular}{|c|c|c|c|c|c|c|c|c|c|c|}
\hline \multirow{3}{*}{ Variable } & \multirow{3}{*}{ Subcategory } & \multicolumn{6}{|c|}{ Salty Taste Preference } & \multirow[b]{2}{*}{ Total } & \multirow{3}{*}{$\begin{array}{c}\text { Test } \\
\text { Statistic }\end{array}$} & \multirow{3}{*}{$p$-Value } \\
\hline & & \multicolumn{2}{|c|}{$\begin{array}{c}\text { Neutral } \\
(n=60,533)\end{array}$} & \multicolumn{2}{|c|}{$\begin{array}{c}\text { Blandly } \\
(n=27,292)\end{array}$} & \multicolumn{2}{|c|}{$\begin{array}{c}\text { Salty } \\
(n=27,753)\end{array}$} & & & \\
\hline & & $n$ & Proportior & n $n$ & Proportion & $n$ & Proportior & n $n$ & & \\
\hline \multirow{8}{*}{ Age } & $19-29$ & 6017 & 47.6 & 2618 & 20.7 & 4002 & 31.7 & 12,637 & \multirow{8}{*}{73.361} & \multirow{8}{*}{$<0.001$} \\
\hline & $30-39$ & 9511 & 53 & 4625 & 25.8 & 3815 & 21.3 & 17,951 & & \\
\hline & $40-49$ & 12,206 & 56.3 & 5307 & 24.5 & 4180 & 19.3 & 21,693 & & \\
\hline & $50-59$ & 12,443 & 55.3 & 5647 & 25.1 & 4392 & 19.5 & 22,482 & & \\
\hline & $60-69$ & 9465 & 51.9 & 3945 & 21.6 & 4833 & 26.5 & 18,243 & & \\
\hline & $70-79$ & 8101 & 48.6 & 3695 & 22.2 & 4875 & 29.2 & 16,671 & & \\
\hline & $80-89$ & 2555 & 47.4 & 1325 & 24.6 & 1515 & 28.1 & 5395 & & \\
\hline & 90 or higher & 235 & 46.4 & 130 & 25.7 & 141 & 27.9 & 506 & & \\
\hline \multirow{3}{*}{ Marital Status } & Married & 40,945 & 54.3 & 18,119 & 24 & 16,318 & 21.6 & 75,382 & \multirow{3}{*}{151.429} & \multirow{3}{*}{$<0.001$} \\
\hline & $\begin{array}{l}\text { Separated, } \\
\text { divorced, } \\
\text { widowed }\end{array}$ & 13,138 & 49 & 6330 & 23.6 & 7359 & 27.4 & 26,827 & & \\
\hline & Unmarried & 6450 & 48.2 & 2843 & 21.3 & 4076 & 30.5 & 13,369 & & \\
\hline \multirow{4}{*}{$\begin{array}{l}\text { Education } \\
\text { Level }\end{array}$} & $\begin{array}{c}\text { Elementary } \\
\text { graduate or lower }\end{array}$ & 10,072 & 47.9 & 4370 & 20.8 & 6589 & 31.3 & 21,031 & \multirow{4}{*}{75.288} & \multirow{4}{*}{$<0.001$} \\
\hline & $\begin{array}{l}\text { Middle school } \\
\text { graduate }\end{array}$ & 10,716 & 53 & 4170 & 20.6 & 5326 & 26.4 & 20,212 & & \\
\hline & $\begin{array}{l}\text { High school } \\
\text { graduate }\end{array}$ & 6865 & 55.4 & 2816 & 22.7 & 2709 & 21.9 & 12,390 & & \\
\hline & $\begin{array}{l}\text { College graduate } \\
\text { or higher }\end{array}$ & 32,880 & 53.1 & 15,936 & 25.7 & 13,129 & 21.2 & 61,945 & & \\
\hline \multirow{4}{*}{$\begin{array}{l}\text { Household } \\
\text { income }\end{array}$} & $\begin{array}{c}\text { 1st Quartile } \\
\text { (lowest) }\end{array}$ & 16,326 & 50.2 & 7263 & 22.3 & 8944 & 27.5 & 32,533 & \multirow{4}{*}{22.796} & \multirow{4}{*}{$<0.001$} \\
\hline & 2nd Quartile & 16,770 & 53.1 & 7343 & 23.3 & 7452 & 23.6 & 31,565 & & \\
\hline & 3rd Quartile & 13,920 & 54 & 6107 & 23.7 & 5731 & 22.2 & 25,758 & & \\
\hline & $\begin{array}{l}\text { 4th Quartile } \\
\text { (highest) }\end{array}$ & 13,517 & 52.6 & 6579 & 25.6 & 5626 & 21.9 & 25,722 & & \\
\hline \multirow{3}{*}{$\begin{array}{l}\text { Residential } \\
\text { area }\end{array}$} & Capital & 5882 & 51.8 & 2887 & 25.4 & 2597 & 22.8 & 11,366 & \multirow{3}{*}{2.617} & \multirow{3}{*}{0.035} \\
\hline & Urban & 11,789 & 51.6 & 5606 & 24.5 & 5450 & 23.9 & 22,845 & & \\
\hline & Rural & 42,862 & 52.7 & 18,799 & 23.1 & 19,706 & 24.2 & 81,367 & & \\
\hline \multirow{2}{*}{ Hypertension } & No & 46,748 & 53.3 & 20,789 & 23.7 & 20,155 & 23 & 87,692 & \multirow{2}{*}{37.078} & \multirow{2}{*}{$<0.001$} \\
\hline & Yes & 13,785 & 49.4 & 6503 & 23.3 & 7598 & 27.2 & 27,886 & & \\
\hline \multirow{2}{*}{ Diabetes } & No & 55,878 & 52.7 & 24,833 & 23.4 & 25,318 & 23.9 & 106,029 & \multirow{2}{*}{11.9} & \\
\hline & Yes & 4655 & 48.7 & 2459 & 25.8 & 2435 & 25.5 & 9549 & & $<0.001$ \\
\hline
\end{tabular}


Table 1. Cont.

\begin{tabular}{|c|c|c|c|c|c|c|c|c|c|c|}
\hline \multirow{3}{*}{ Variable } & \multirow{3}{*}{ Subcategory } & \multicolumn{6}{|c|}{ Salty Taste Preference } & \multirow[b]{2}{*}{ Total } & \multirow{3}{*}{$\begin{array}{c}\text { Test } \\
\text { Statistic }\end{array}$} & \multirow{3}{*}{$p$-Value } \\
\hline & & \multicolumn{2}{|c|}{$\begin{array}{c}\text { Neutral } \\
(n=60,533)\end{array}$} & \multicolumn{2}{|c|}{$\begin{array}{c}\text { Blandly } \\
(n=27,292)\end{array}$} & \multicolumn{2}{|c|}{$\begin{array}{c}\text { Salty } \\
(n=27,753)\end{array}$} & & & \\
\hline & & $n$ & Proportior & n $n$ & Proportion & n $n$ & Proportio & on $n$ & & \\
\hline \multirow{2}{*}{ Dyslipidemia } & No & 54,013 & 52.6 & 24,233 & 23.6 & 24,396 & 23.8 & 102,642 & \multirow{2}{*}{4.452} & \multirow{2}{*}{0.012} \\
\hline & Yes & 6520 & 50.4 & 3059 & 23.6 & 3357 & 26 & 12,936 & & \\
\hline \multirow{3}{*}{$\begin{array}{l}\text { Breakfast } \\
\text { eating } \\
\text { (weekly) }\end{array}$} & 5-7 days & 48,928 & 52.8 & 22,685 & 24.5 & 21,140 & 22.8 & 92,753 & \multirow{3}{*}{122.33} & \multirow{3}{*}{$<0.001$} \\
\hline & $1-4$ days & 6813 & 52.1 & 2618 & 20 & 3642 & 27.9 & 13,073 & & \\
\hline & Never & 4792 & 49.1 & 1989 & 20.4 & 2971 & 30.5 & 9752 & & \\
\hline \multirow{3}{*}{$\begin{array}{l}\text { OABSS- } \\
\text { daytime } \\
\text { frequency }\end{array}$} & $\leq 7$ & 47,237 & 53.3 & 20,644 & 23.3 & 20,700 & 23.4 & 88,581 & \multirow{3}{*}{20.352} & \multirow{3}{*}{$<0.001$} \\
\hline & $8 \sim 14$ & 12,589 & 49.7 & 6223 & 24.6 & 6534 & 25.8 & 25,346 & & \\
\hline & $\geq 15$ & 707 & 42.8 & 425 & 25.7 & 519 & 31.4 & 1651 & & \\
\hline \multirow{4}{*}{$\begin{array}{l}\text { OABSS- } \\
\text { nighttime } \\
\text { frequency) }\end{array}$} & 0 & 26,636 & 53.8 & 12,218 & 24.7 & 10,672 & 21.5 & 49,526 & \multirow{4}{*}{33.066} & \multirow{4}{*}{$<0.001$} \\
\hline & 1 & 20,560 & 53.4 & 8856 & 23 & 9099 & 23.6 & 38,515 & & \\
\hline & 2 & 8227 & 49.8 & 3753 & 22.7 & 4536 & 27.5 & 16,516 & & \\
\hline & $\geq 3$ & 5110 & 46.4 & 2465 & 22.4 & 3446 & 31.3 & 11,021 & & \\
\hline \multirow{6}{*}{$\begin{array}{l}\text { OABSS- } \\
\text { urgency }\end{array}$} & None & 51,924 & 53.2 & 23,187 & 23.8 & 22,403 & 23 & 97,514 & \multirow{6}{*}{24.416} & \multirow{6}{*}{$<0.001$} \\
\hline & $\begin{array}{c}\text { Less than once a } \\
\text { week }\end{array}$ & 4702 & 49.8 & 2081 & 22 & 2655 & 28.1 & 9438 & & \\
\hline & $\begin{array}{c}\text { Once a week or } \\
\text { more }\end{array}$ & 1895 & 46.8 & 910 & 22.5 & 1244 & 30.7 & 4049 & & \\
\hline & About once a day & 955 & 46.2 & 486 & 23.5 & 626 & 30.3 & 2067 & & \\
\hline & 2-4 times a day & 687 & 41.5 & 403 & 24.4 & 564 & 34.1 & 1654 & & \\
\hline & $\begin{array}{l}5 \text { times a day or } \\
\text { more }\end{array}$ & 370 & 43.2 & 225 & 26.3 & 261 & 30.5 & 856 & & \\
\hline \multirow{6}{*}{$\begin{array}{l}\text { OABSS_urge } \\
\text { incontinence }\end{array}$} & None & 55,147 & 53 & 24,653 & 23.7 & 24,319 & 23.4 & 104,119 & \multirow{6}{*}{15.789} & \multirow{6}{*}{$<0.001$} \\
\hline & $\begin{array}{c}\text { Less than once a } \\
\text { week }\end{array}$ & 3052 & 49 & 1402 & 22.5 & 1772 & 28.5 & 6226 & & \\
\hline & $\begin{array}{c}\text { Once a week or } \\
\text { more }\end{array}$ & 1186 & 46.3 & 577 & 22.5 & 801 & 31.2 & 2564 & & \\
\hline & About once a day & 575 & 43.7 & 305 & 23.2 & 435 & 33.1 & 1315 & & \\
\hline & 2-4 times a day & 400 & 41.5 & 258 & 26.8 & 305 & 31.7 & 963 & & \\
\hline & $\begin{array}{l}5 \text { times a day or } \\
\text { more }\end{array}$ & 173 & 44.2 & 97 & 24.8 & 121 & 30.9 & 391 & & \\
\hline \multirow{3}{*}{ OAB severity } & Mild & 57,529 & 52.9 & 25,655 & 23.6 & 25,585 & 23.5 & 108,769 & \multirow{3}{*}{33.409} & \\
\hline & Moderate & 2645 & 44.5 & 1412 & 23.8 & 1883 & 31.7 & 5940 & & $<0.001$ \\
\hline & Severe & 359 & 41.3 & 225 & 25.9 & 285 & 32.8 & 869 & & \\
\hline
\end{tabular}

$\mathrm{OAB}$, overactive bladder; OABSS, overactive bladder symptom score.

A JCA coordinate plot illustrates multifactorial relationship between overactive bladder symptom, salty taste preference, socioeconomic, comorbidity, and dietary behavior. The left-lower quadrant shows the association between respondents those who prefer salty taste and moderate or severe STORAGE symptom. On the other side, participants who reported their salty taste preference as blandly or neutral, and mild storage symptom were clustered in the right-upper quadrant, close to the centroid. It was identified that salty taste preference was associated with storage symptom (Figure 2). 


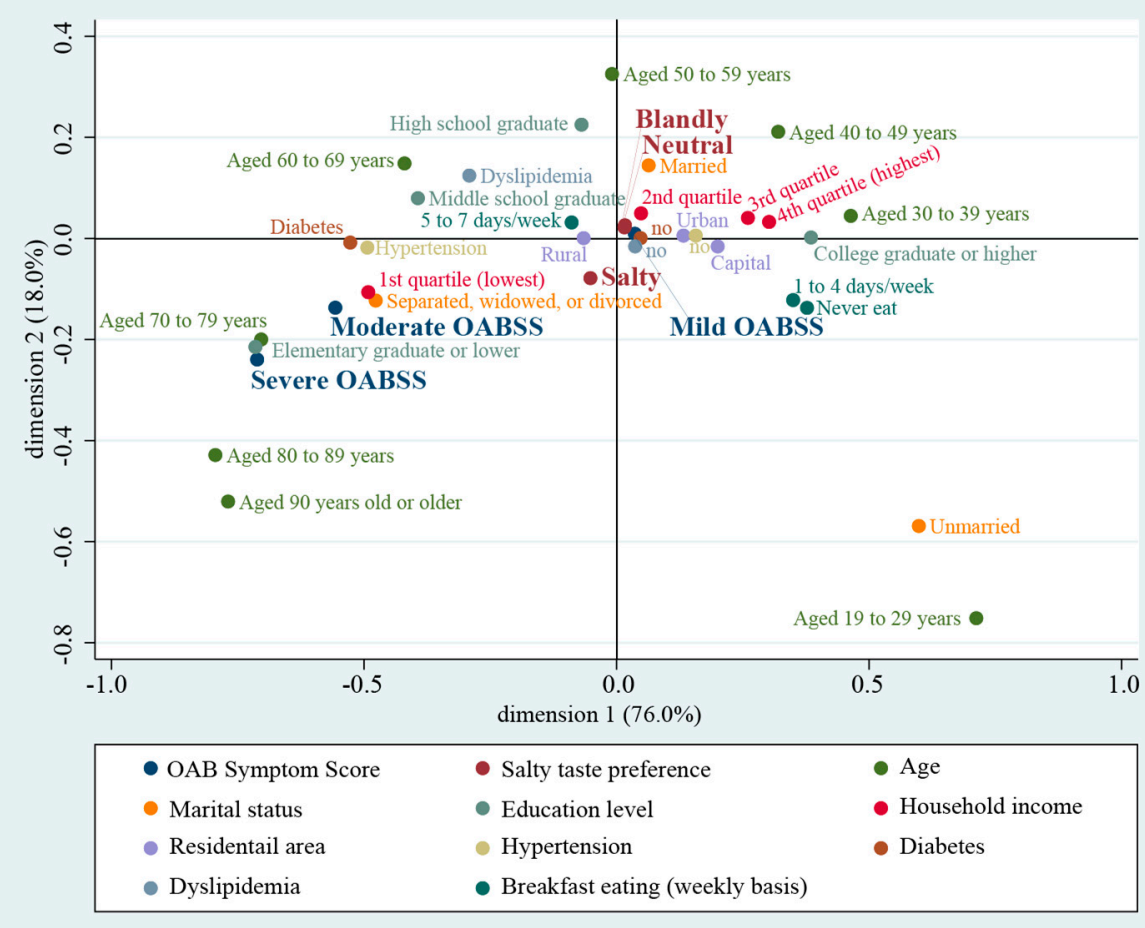

coordinates in principal normalization

Figure 2. Multifactorial relationship between overactive bladder symptom, salty taste preference, socioeconomic, comorbidity, and dietary behavior. OABSS, overactive bladder symptom score.

Result from multivariable adjusted negative binomial model to investigate the relationship between OABSS and salty taste preference among Korean female adults suggests that participants those who prefer blandly, or salty taste preference were both associated with increased OABSS. Participants who reported their salty taste preference as blandly and salty were indicates $7.1 \%(\operatorname{IRR}=1.071, p<0.001,95 \% \mathrm{CI}=1.045$ to 1.097$)$ and $20.5 \%$ (IRR $=1.205, p<0.001,95 \% \mathrm{CI}=1.177$ to 1.234$)$ increased likelihood of worse OABSS condition compared with participants those who reported their salty taste preference as neutral in multivariable adjusted model (Table 2).

Table 2. Impact of salty taste preference on overactive bladder symptom among South Korean female adults.

\begin{tabular}{|c|c|c|c|c|c|c|c|c|c|c|}
\hline \multirow{3}{*}{ Salty Taste Preference } & \multicolumn{10}{|c|}{ Overactive Bladder Symptom Score (Score Range $=0$ to 15) } \\
\hline & \multicolumn{5}{|c|}{ Age-Adjusted } & \multicolumn{5}{|c|}{ Multivariable Adjusted } \\
\hline & IRR & $\begin{array}{l}\text { Linearized } \\
\text { SE }\end{array}$ & $p$-Value & \multicolumn{2}{|c|}{$95 \% \mathrm{CI}$} & IRR & $\begin{array}{c}\text { Linearized } \\
\text { SE }\end{array}$ & $p$-Value & \multicolumn{2}{|c|}{$95 \% \mathrm{CI}$} \\
\hline Neutral & (Ref) & & & & & (Ref) & & & & \\
\hline Blandly & 1.065 & 0.013 & $<0.001$ & 1.039 & 1.092 & 1.071 & 0.013 & $<0.001$ & 1.045 & 1.097 \\
\hline Salty & 1.236 & 0.012 & $<0.001$ & 1.207 & 1.267 & 1.205 & 0.015 & $<0.001$ & 1.177 & 1.234 \\
\hline
\end{tabular}

IRR, incidence rate ratios; CI, confidence interval; SE, standard error; Ref, reference. The KCHS as a sample survey was analyzed by study subject and with applied weight calculated in production of the sample design weight and benchmark weight. Strata with single sampling unit centered at overall mean. Sample size $=115,578$; weighted $=18,388,103$. Multivariable model was additionally adjusted for marital status, education level, household income, residential area, hypertension, diabetes mellitus, dyslipidemia, and breakfast eating.

\section{Discussion}

It is an established fact that sodium predilection worsens HTN and makes it more likely for CVD patients to die, so it can affect the circulatory system and therefore demands close attention $[19,20]$. HTN, metabolic syndrome, atherosclerosis, fatty liver, and storage 
symptom are all interconnected. Hence, it can be said that storage symptom is subject to the influence of both HTN and other elements of the circulatory system.

The evidentiary support that has been generated so far about the correlation amongst sodium intake/predilection and LUTS seriousness is not extensive and stems primarily from research on male individuals. Therefore, the present work seeks to expand the topic to female individuals. In cross-sectional examination of a population sampled arbitrarily revealed that sodium intake and LUTS were significantly positively correlated 2. A trend that was particularly significant for storage LUTS was that the probability of graver LUTS has higher in male individuals consuming elevated amount of sodium (OR $=2.25 ; 95 \%$ $\mathrm{CI}=1.26-4.03$ ), but no definitive correlation was established regarding voiding LUTS. In a different study with case-control design, BPH open to surgical treatment was more likely to be diagnosed $(\mathrm{OR}=1.30)$ in cases of sodium intake [11].

The International Prostate Symptom Score (IPSS) applied in our previous work confirmed that sodium intake and storage symptom were correlated in male [12]. More specifically, unlike the group with neutral sodium predilection, the group with a predilection for salty taste demonstrated a significant correlation not only with elevated IPSS total score (Coef $=0.31 ; 95 \%$ CI: 0.27, 0.35), but also heightened risk of serious IPSS grade $(\mathrm{OR}=1.46$; 95\% CI:1.35, 1.57), heightened IPSS voiding score (Coef $=0.38 ; 95 \%$ CI: 0.32, 0.44 ), heightened IPSS storage score (Coef $=0.25$; 95\% CI: $0.22,0.29$ ), as well as being more likely to develop symptoms of IPSS nocturia (OR $=1.21 ; 95 \%$ CI:1.16, 1.27).

In a recent comprehensive cross-sectional study, a positive correlation was established between sodium intake per day and both day-time and night-time frequency. This correlation was attributed primarily to polydipsia associated with sodium intake as this elevated blood osmotic pressure. Furthermore, the study did not undertake sex-based subgroup analysis, even though, of the total of 321 participants employed, 219 were female [21].

In the present study, by comparison to respondents indicating a neutral predilection for salty taste, those who indicated a predilection for bland and salty taste were $7.1 \%$ $(\mathrm{IRR}=1.071, p<0.001,95 \% \mathrm{CI}=1.045-1.097)$ and $20.5 \%(\mathrm{IRR}=1.205, p<0.001,95 \%$ $\mathrm{CI}=1.177-1.234)$ more probable to experience severe storage symptom, within an adjusted model with multiple variables. Furthermore, JCA was conducted as multifactorial analysis, confirming the existence of a correlation between predilection for salty taste and both moderately and highly severe storage symptom.

Supported by a number of empirical studies [4,9], sodium intake stimulating the bladder epithelium directly is the traditional interpretation given for the correlation between sodium intake and storage symptom. According to Yamamoto and colleagues, the bladder epithelium sodium channel is upregulated as a result of elevated sodium intake [4]. Moreover, storage symptom worsening when bladder afferent pathways are irregularly activated can be attributed to the discharge of neurotransmitters and other bioactive substances from the bladder epithelium when the latter is stimulated [22]. It is noteworthy that the upregulation of the sodium channel of the bladder epithelium and urinary storage symptom are closely correlated [23].

Despite its significant results, the present study is not without shortcomings. One major shortcoming is that the causal effect of sodium intake on OAB seriousness cannot be determined through cross-sectional analysis. Another shortcoming is that the work did not include BMI data and, so far, BMI and OAB seriousness have not been definitively correlated, despite some evidentiary support for the association between obesity and LUTS seriousness [24]. Additionally, the use of a subjective questionnaire to establish the extent of sodium intake constitutes a shortcoming as well. Previous research emphasised the significance of determining sodium levels in urine for accurately quantifying the sodium intake extent [6]. The levels of urinary sodium were not measured in the present work, but the correlation amongst these levels and self-appraised sodium predilection scale has been proven in other studies. For instance, a self-evaluation questionnaire comprising 127 items about dish frequency indicated that sodium predilection, real sodium intake, and likelihood of increased sodium intake were significantly correlated [25]. Similarly, a correlation was 
found between salty taste thresholds in healthy individuals and individuals with nondialysis CKD and salty taste thresholds and sodium levels in urine [26]. Moreover, our study is providing lacking information about $\mathrm{OAB}$ symptoms secondary to bladder outlet obstruction due to pelvic organ prolapse that is frequently observed in obese and old women [27].

A final shortcoming is that the study did not include participants with inadequate dietary customs owing to lack of data about socio-economic factors. Nutritional quality or dietary habits are likely to be suboptimal in individuals who do not disclose income or education information as they usually have a low socio-economic standing.

\section{Conclusions}

A correlation was established between sodium preference and OAB seriousness, with both excessive and poor sodium intake contributing to LUTS worsening by comparison to neutral sodium intake. This study showed indirect evidence of relationship between sodium intake and OAB severity. Furthermore, sodium preference was found to have an association with lifestyle and socio-economic factors as well. To solidify these findings, further prospective studies must be conducted.

Author Contributions: Conceptualization, J.-W.N. and J.H.K.; methodology, J.-W.N., K.-B.K., Y.D.K.; formal analysis, J.-W.N. and K.-B.K.; investigation, J.-W.N.; resources, J.-W.N.; data curation, K.-B.K.; writing—original draft preparation, J.W.N. and J.H.K.; writing—review and editing, J.W.N., K.-B.K., J.H.K. and Y.D.K.; supervision, Y.D.K.; project administration, J.-W.N. and Y.D.K.; funding acquisition, J.-W.N. All authors have read and agreed to the published version of the manuscript.

Funding: The present research was supported by the research fund of Dankook University in 2020.

Institutional Review Board Statement: Ethical review from the Institutional Review Board of Soonchunhyang University Seoul Hospital (No. 2018-07-017) and approval were waived for this study due to open accessibility at the national public repository (http:/ / chs.cdc.go.kr) of the KCHS data. Moreover, there are no confidentiality risks to the participants of this study because the survey data were completely anonymized.

Informed Consent Statement: Not applicable.

Data Availability Statement: Not applicable.

Acknowledgments: The present research was supported by the research fund of Dankook University in 2020 .

Conflicts of Interest: The authors declare no conflict of interest.

\section{References}

1. Liu, Z.M.; Wong, C.K.; Chan, D.; Tse, L.A.; Yip, B.; Wong, S.Y. Fruit and Vegetable Intake in Relation to Lower Urinary Tract Symptoms and Erectile Dysfunction Among Southern Chinese Elderly Men: A 4-Year Prospective Study of Mr OS Hong Kong. Medicine (Baltimore) 2016, 95, e2557. [CrossRef] [PubMed]

2. Maserejian, N.N.; Giovannucci, E.L.; McKinlay, J.B. Dietary macronutrients, cholesterol, and sodium and lower urinary tract symptoms in men. Eur. Urol. 2009, 55, 1179-1189. [CrossRef] [PubMed]

3. Sugaya, K.; Kadekawa, K.; Ikehara, A.; Nakayama, T.; Gakiya, M.; Nashiro, F.; Goya, M.; Hatano, T.; Ogawa, Y. Influence of hypertension on lower urinary tract symptoms in benign prostatic hyperplasia. Int. J. Urol. 2003, 10, 569-574. [CrossRef] [PubMed]

4. Yamamoto, S.; Hotta, Y.; Maeda, K.; Kataoka, T.; Maeda, Y.; Hamakawa, T.; Shibata, Y.; Sasaki, S.; Ugawa, S.; Yasui, T.; et al. High salt loading induces urinary storage dysfunction via upregulation of epithelial sodium channel alpha in the bladder epithelium in Dahl salt-sensitive rats. J. Pharmacol. Sci. 2017, 135, 121-125. [CrossRef]

5. Graudal, N.; Jurgens, G.; Baslund, B.; Alderman, M.H. Compared with usual sodium intake, low- and excessive-sodium diets are associated with increased mortality: A meta-analysis. Am. J. Hypertens. 2014, 27, 1129-1137. [CrossRef]

6. O'Donnell, M.; Mente, A.; Rangarajan, S.; McQueen, M.J.; Wang, X.; Liu, L.; Yan, H.; Lee, S.F.; Mony, P.; Devanath, A.; et al. Urinary sodium and potassium excretion, mortality, and cardiovascular events. N. Engl. J. Med. 2014, 371, 612-623. [CrossRef]

7. Yoshimura, K.; Terada, N.; Matsui, Y.; Terai, A.; Kinukawa, N.; Arai, Y. Prevalence of and risk factors for nocturia: Analysis of a health screening program. Int. J. Urol. 2004, 11, 282-287. [CrossRef] 
8. Ito, H.; Yoshiyasu, T.; Yamaguchi, O.; Yokoyama, O. Male Lower Urinary Tract Symptoms: Hypertension as a Risk Factor for Storage Symptoms, but Not Voiding Symptoms. Low. Urin. Tract Symptoms 2012, 4, 68-72. [CrossRef]

9. Kurokawa, T.; Zha, X.; Ito, H.; Aoki, Y.; Akino, H.; Kobayashi, M.; Yokoyama, O. Underlying mechanisms of urine storage dysfunction in rats with salt-loading hypertension. Life Sci. 2015, 141, 8-12. [CrossRef]

10. Wyss, J.M. Pathways by which dietary salt affects blood pressure and the nervous system. Hypertension 2006, 47, 638-639. [CrossRef]

11. Tavani, A.; Longoni, E.; Bosetti, C.; Maso, L.D.; Polesel, J.; Montella, M.; Ramazzotti, V.; Negri, E.; Franceschi, S.; La Vecchia, C. Intake of selected micronutrients and the risk of surgically treated benign prostatic hyperplasia: A case-control study from Italy. Eur. Urol. 2006, 50, 549-554. [CrossRef] [PubMed]

12. Noh, J.W.; Kim, K.B.; Kwon, Y.D.; Kim, J.H. Association between sodium intake and lower urinary tract symptoms: Does less sodium intake have a favorable effect or not? Transl. Androl. Urol. 2020, 9, 1135-1145. [CrossRef] [PubMed]

13. Kang, Y.W.; Ko, Y.S.; Kim, Y.J.; Sung, K.M.; Kim, H.J.; Choi, H.Y.; Sung, C.; Jeong, E. Korea Community Health Survey Data Profiles. Osong Public Health Res. Perspect. 2015, 6, 211-217. [CrossRef] [PubMed]

14. Jeong, S.J.; Homma, Y.; Oh, S.J. Korean version of the overactive bladder symptom score questionnaire: Translation and linguistic validation. Int. Neurourol. J. 2011, 15, 135-142. [CrossRef] [PubMed]

15. Homma, Y.; Yoshida, M.; Seki, N.; Yokoyama, O.; Kakizaki, H.; Gotoh, M.; Yamanishi, T.; Yamaguchi, O.; Takeda, M.; Nishizawa, O. Symptom assessment tool for overactive bladder syndrome-Overactive bladder symptom score. Urology 2006, 68, 318-323. [CrossRef]

16. Lim, S.; Shin, H.; Song, J.H.; Kwak, S.H.; Kang, S.M.; Won Yoon, J.; Choi, S.H.; Cho, S.I.; Park, K.S.; Lee, H.K.; et al. Increasing prevalence of metabolic syndrome in Korea: The Korean National Health and Nutrition Examination Survey for 1998-2007. Diabetes Care 2011, 34, 1323-1328. [CrossRef]

17. Sourial, N.; Wolfson, C.; Zhu, B.; Quail, J.; Fletcher, J.; Karunananthan, S.; Bandeen-Roche, K.; Béland, F.; Bergman, H. Correspondence analysis is a useful tool to uncover the relationships among categorical variables. J. Clin. Epidemiol. 2010, 63, 638-646. [CrossRef]

18. Higgs, N. Practical and innovative uses of correspondence analysis. J. R. Stat. Soc. Ser. D (Stat.) 1991, 40, 183-194. [CrossRef]

19. Graudal, N.A.; Hubeck-Graudal, T.; Jurgens, G. Effects of low sodium diet versus high sodium diet on blood pressure, renin, aldosterone, catecholamines, cholesterol, and triglyceride. Cochrane Database Syst. Rev. 2017, 4, CD004022. [CrossRef]

20. Nerbass, F.B.; Pecoits-Filho, R.; McIntyre, N.J.; McIntyre, C.W.; Taal, M.W. High sodium intake is associated with important risk factors in a large cohort of chronic kidney disease patients. Eur. J. Clin. Nutr. 2015, 69, 786-790. [CrossRef]

21. Matsuo, T.; Miyata, Y.; Sakai, H. Effect of salt intake reduction on nocturia in patients with excessive salt intake. Neurourol. Urodyn. 2019, 38, 927-933. [CrossRef] [PubMed]

22. Gonzalez, E.J.; Merrill, L.; Vizzard, M.A. Bladder sensory physiology: Neuroactive compounds and receptors, sensory transducers, and target-derived growth factors as targets to improve function. Am. J. Physiol. Regul. Integr. Comp. Physiol. 2014, 306, R869-R878. [CrossRef] [PubMed]

23. Araki, I.; Du, S.; Kamiyama, M.; Mikami, Y.; Matsushita, K.; Komuro, M.; Furuya, Y.; Takeda, M. Overexpression of epithelial sodium channels in epithelium of human urinary bladder with outlet obstruction. Urology 2004, 64, 1255-1260. [CrossRef] [PubMed]

24. Kim, J.H.; Sun, H.Y.; Park, S.Y.; Soh, M.J.; Kim, Y.J.; Song, Y.S. Association between obesity and lower urinary tract symptoms: Propensity score matching study between healthy controls and obese patients seeking bariatric surgery. Surg. Obes Relat. Dis. 2016, 12, 1585-1593. [CrossRef] [PubMed]

25. Shim, E.; Yang, Y.J.; Yang, Y.K. Relationship between thresholds and self-assessed preference for saltiness and sodium intake in young women. J. Nutr. Health 2016, 49, 88-98. [CrossRef]

26. Kim, T.H.; Kim, Y.H.; Bae, N.Y.; Kang, S.S.; Lee, J.B.; Kim, S.B. Salty taste thresholds and preference in patients with chronic kidney disease according to disease stage: A cross-sectional study. Nutr. Diet. 2018, 75, 59-64. [CrossRef]

27. Boer, T.A.; Salvatore, S.; Cardozo, L.; Chapple, C.; Kelleher, C.; van Kerrebroeck, P.; Kirby, M.G.; Koelbl, H.; Espuna-Pons, M.; Milsom, I.; et al. Pelvic organ prolapse and overactive bladder. Neurourol. Urodyn. 2010, 29, 30-39. [CrossRef] 